\title{
Genexpert test and endometrial histological findings in infertile women
}

\author{
Roopakshi Garg*, Neelima Agarwal, Manisha Gupta,
}

Department of Obstetrics and Gynecology, Santosh Medical College and Hospital, Ghaziabad, Uttar Pradesh, India

Received: 26 January 2018

Accepted: 28 February 2018

\section{*Correspondence:}

Dr. Roopakshi Garg,

E-mail: drroopakshi@gmail.com

Copyright: (c) the author(s), publisher and licensee Medip Academy. This is an open-access article distributed under the terms of the Creative Commons Attribution Non-Commercial License, which permits unrestricted non-commercial use, distribution, and reproduction in any medium, provided the original work is properly cited.

\section{ABSTRACT}

Background: Infertility is a worldwide health problem with very definite physiological, psychological and social implications. According to studies, about $30 \%$ of infertility cases are due to the male factors, 40 to $50 \%$ have the origin of female factors and 20 to $30 \%$ of cases are caused by both male and female factors. Genital tuberculosis is among the main causes of female infertility. Due to its high prevalence, especially in developing countries, work-up of an infertile couple should include evaluation for tuberculosis irrespective of history or exposure. The objective of the present study is to find out the prevalence of genital tuberculosis in all females presenting with infertility in a tertiary care hospital over a given period of time, and diagnostic comparison of endometrial tuberculosis by GeneXpert and Histopathological examination (HPE).

Methods: The prospective observational study was conducted from January 2016-June 2017.A total of 81 endometrial tissue samples were collected from the women, satisfying the inclusion and exclusion criteria.

Results: GeneXpert scored negative in our study. On HPE, out of 81 patients, proliferative endometrium (anovulatory) was found in 34 cases (41.9\%), non-specific endometritis in 1 case $(1.23 \%)$ and 1 case $(1.23 \%)$ was found positive for tubercular endometritis. Secretory endometrium was found in 45 cases $(55.55 \%)$.

Conclusions: Endometrial biopsy shows not only the tuberculous endometritis, but also gives additional information about hormone response of endometrium, local factors of endometrium concerning non-specific and specific infections and anovulatory cycles. Gene Expert if positive on endometrial biopsy is a reliable test for FGTB and treatment can be started on its basis.

Keywords: Endometrial biopsy, Female genital tuberculosis, Infertility, GeneXpert test, Histopathological examination

\section{INTRODUCTION}

WHO has defined infertility as "failure to conceive despite over 12 months of regular and unprotected intercourse". Tubal infertility is a very important factor constituting about $30-40 \%$ of cases. Tuberculosis, a chronic infectious disease, is one of the major etiological factors of female tubal infertility. ${ }^{1}$

According to Global TB Report 2016, there were estimated 10.4 million new tuberculosis (TB) cases worldwide (3.5 million in women), with 2 million deaths. $^{2}$ It is estimated that $5-10 \%$ of infertile women over the world has genital tuberculosis although the incidence varies from less than $1 \%$ in the United States to nearly $18 \%$ in India.

The empirical use of ATT (anti-tubercular therapy) in infertile women without any diagnostic evidence has led to resistance.

Unlike pulmonary tuberculosis, the clinical diagnosis of genital tuberculosis is difficult because in majority of cases, the disease is either asymptomatic or has varied 
clinical presentation. Routine laboratory investigations like microscopy and culture are of little value in the diagnosis.

PCR (Polymerase chain reaction) has highest sensitivity as compared to other methods for diagnosis of tuberculosis but due to false positive results, specificity is low. ${ }^{3}$ Only histopathological evidence in premenstrual endometrial tissue biopsy can provide diagnosis with certainty.

GeneXpert MTB/RIF has potentially led to revolution in diagnosis of active tuberculosis disease and MDR-TB (multidrug resistance tuberculosis). WHO recommended use of Xpert assay by 'December 2010'. ${ }^{4}$ It is an important breakthrough in fight against tuberculosis.

The present study evaluates the prevalence of FGTB among infertile patients. Study aimed at evaluating the histological patterns of endometrium in infertile women in an attempt to establish the cause of infertility. It has also been designed to evaluate the efficacy of GeneXpert test for diagnosing endometrial tuberculosis.

\section{METHODS}

The prospective observational study was conducted from January 2016 to June 2017 in the Department of Obstetrics and Gynaecology of Santosh medical college and hospital, Ghaziabad, U.P. India.

On the basis of the clinical presentation, 81 women with primary or secondary infertility were included. Exclusion criteria were endometriosis, fibroid, cervical polyp and sexually transmitted disease. Informed consent was taken from each participant.

Patients were called for endometrial aspiration or biopsy one week before start of menstrual cycle or within 12 hours of onset of menses. Patients were advised abstinence in menstrual cycle before the month of procedure. Two samples were taken by Karmann's cannula number 4 or endometrial biopsy curette. One sample was sent for HPE [histopathological Examination] in formalin in department of pathology, Santosh medical college and hospital; second sample in normal saline for GeneXpert test to 'New Delhi Tuberculosis Centre' [NDTB Centre, Delhi]. The results of the two were analysed and compared.

\section{RESULTS}

Eighty-one patients with primary or secondary infertility were recruited for the study.

Table 1 describes the baseline characteristic of the study participants. The mean age of the study participants was 28.11 years $(\mathrm{SD} \pm 4.70)$ with the range of 20 to 40 years. Maximum patients were from age group 26-30 years $(43.20 \%)$ (Table 1).
Table 1: Socio-demographic factors of the patients.

\begin{tabular}{|l|lll|}
\hline Characteristic & & n=81 & $\%$ \\
& $\leq 20$ years & 4 & 4.9 \\
\hline \multirow{3}{*}{ Age } & $21-25$ & 22 & 27.1 \\
& $26-30$ & 35 & 43.3 \\
\hline & $31-34$ & 14 & 17.3 \\
\hline \multirow{2}{*}{ Religion } & Muslim & 13 & 16.1 \\
\hline \multirow{2}{*}{ Family history of TB } & Hindu & 68 & 83.9 \\
\hline \multirow{2}{*}{ Past history of TB } & Yes & 10 & 11.2 \\
\cline { 2 - 3 } & No & 71 & 88.8 \\
\hline & Yes & 19 & 23.5 \\
\cline { 2 - 4 } & No & 62 & 76.5 \\
\hline
\end{tabular}

Out of 81 women from the study population, $53.08 \%$ were secondary infertility patients and $46.91 \%$ were primary infertility patients (Table 2 ).

Table 2: Distribution according to type of infertility.

\begin{tabular}{|lll|}
\hline Type of infertility & $\mathrm{n}=\mathbf{8 1}$ & $\%$ \\
\hline Primary & 38 & 46.9 \\
\hline Secondary & 43 & 53.1 \\
\hline
\end{tabular}

GeneXpert test scored negative in our study. On histopathological examination of endometrium, 1 case $(1.23 \%)$ was found positive for tubercular endometritis, proliferative endometrium (anovulatory) was found in 34 cases (41.9\%), non-specific endometritis in 1 case $(1.23 \%)$ and. Secretory endometrium was found in 45 cases $(55.55 \%)$ (Table 3$)$.

Table 3: Results of genexpert and histopathology.

\begin{tabular}{|c|c|c|c|}
\hline Investigation & & $\mathrm{n}=\mathbf{8 1}$ & $\%$ \\
\hline \multirow{2}{*}{$\begin{array}{l}\text { Genexpert } \\
\text { test }\end{array}$} & Positive & 0 & 0 \\
\hline & Negative & 81 & 100 \\
\hline \multirow{4}{*}{$\begin{array}{l}\text { Histology of } \\
\text { Endometrium }\end{array}$} & Secretory Phase & 45 & 55.6 \\
\hline & Proliferative Phase & 34 & 41.9 \\
\hline & $\begin{array}{l}\text { Non-specific } \\
\text { Endometritis }\end{array}$ & 1 & 1.3 \\
\hline & $\begin{array}{l}\text { Tubercular } \\
\text { Endometritis }\end{array}$ & 1 & 1.2 \\
\hline
\end{tabular}

As a secondary outcome, other causes of infertility were also evaluated and compared between primary and secondary infertility patients.

No significant difference was found between two groups in regard to any particular investigation like ESR, Serum TSH, Serum Prolactin, Ultrasound etc.

Proliferative endometrium (anovulatory) was found in 13 cases $(34.21 \%)$ of primary infertility whereas 21 cases $(48.83 \%)$ of secondary infertility, which was more second group. The ' $p$ ' value was 0.18 which was not statistically significant (Table 4). 
Table 4: Other Investigations of infertility.

\begin{tabular}{|c|c|c|c|c|c|}
\hline \multirow{2}{*}{\multicolumn{2}{|c|}{ Investigation }} & \multicolumn{2}{|c|}{ Primary infertility } & \multicolumn{2}{|c|}{ Secondary infertility } \\
\hline & & $\mathbf{n}=\mathbf{3 8}$ & $\%$ & $n=43$ & $\%$ \\
\hline \multicolumn{2}{|c|}{ ESR $(N=0-29)$} & 15 & 39.47 & 14 & 32.5 \\
\hline \multicolumn{2}{|c|}{ S.TSH $(N=0.5-6)$} & 4 & 10.52 & 8 & 18.6 \\
\hline \multicolumn{2}{|c|}{ S. prolactin $(\mathrm{N}=2.8-29.2 \mathrm{NG} / \mathrm{ml})$} & 0 & 0 & 1 & 2.3 \\
\hline \multicolumn{2}{|c|}{ Mantoux test positive } & 32 & 84.2 & 38 & 88.3 \\
\hline \multicolumn{2}{|c|}{ Chest X-ray (S/o TB) } & 1 & 2.6 & 0 & 0 \\
\hline \multicolumn{2}{|c|}{ Husband semen analysis (Abnormal) } & 10 & 26.3 & 10 & 23.2 \\
\hline \multirow{2}{*}{ Ultrasound } & Fibroid & 3 & 7.89 & 1 & 2.3 \\
\hline & PCOD & 11 & 28.9 & 9 & 20.9 \\
\hline \multicolumn{2}{|c|}{ Proliferative endometrium in premenstrual phase } & 13 & 34.21 & 21 & 48.8 \\
\hline \multicolumn{2}{|c|}{ Conceived } & 5 & 13.15 & 6 & 13.9 \\
\hline
\end{tabular}

\section{DISCUSSION}

Due to the lack of specific test and diagnostic modalities, it is difficult to diagnose and conclude the presence of genital tuberculosis. On the basis of clinical presentation women cannot be diagnosed with FGTB.

Multiple imaging techniques are not specific for tuberculosis confirmation. Endometrial biopsy should be taken in premenstrual phase for good results on AFB smear, culture, GeneXpert, PCR and other tests. ${ }^{5}$

Very few studies have been done on GeneXpert as a diagnostic modality for endometrial tuberculosis and hence not much data could be made available to compare our results. GeneXpert scored negative in present study, whereas one study showed $1.6 \%$ positive results. ${ }^{5}$ The sensitivity of Xpert MTB/RIF in detecting TB is quite high (88\%). ${ }^{4}$ GeneXpert if positive on endometrial biopsy is a reliable test for FGTB and treatment can be started on its basis. ${ }^{6}$ The negative predictive value (NPV) is greater than $98 \%$ both in settings with a low prevalence of TB and in those with a high prevalence of TB; that is, a negative result accurately excludes TB in most situations. When XPERT MTB/RIF does not detect M.tuberculosis, the disease can be ruled out in most cases unless there is still a strong suspicion of TB. ${ }^{4}$ Adequate follicular development \& functionally efficient corpus luteum formation are the essential prerequisites for the preparation of good endometrial bed which is essential for successful implantation of blastocyst \& continuation of pregnancy. Histopathological abnormalities in the form of anovulatory endometrium and luteal phase defect forms major cause of infertility.

In this study, secretory endometrium was found in $55.55 \%$ cases, proliferative endometrium (anovulatory) in $41.9 \%$ cases, non-specific endometritis in $1.23 \%$ cases and one case was found positive for tubercular endometritis (1.23\%). In a study by Salma Kafeel et al, most cases were of secretory endometrium (37\%) and $20.95 \%$ cases were of proliferative phase. ${ }^{7}$ In a study by
Geol et al, $2.6 \%$ of patients had their endometrial histopatholgical slides suggestive of tuberculosis, which is less as compare to study by Thangappah et al. ${ }^{3,8} \mathrm{~A}$ study of 100 infertile women by Kohli et al. ${ }^{9}$ showed $4 \%$ positive results on HPE. In another study by Prasad et al. ${ }^{10}$ where they studied 150 infertile women suspected to have genital tuberculosis and subjected them to diagnostic endoscopy, microscopy, histopathology, BACTEC and PCR found $0.66 \%$ positive results on HPE. The differences in the histomorphological patterns of endometrium in various studies may be related to the differences in the geographical pattern and population and period of study. Our results are comparable with various studies done in past. (Table 5)

Table 5: Comparision of percentage of tuberculous endometritium on histopathology.

\begin{tabular}{|lllll|}
\hline Author & Year & Country & (n) & $\begin{array}{l}\text { Positive } \\
(\%)\end{array}$ \\
\hline Prasad et al & 2012 & India & 150 & 0.6 \\
\hline Kafeel S & 2012 & Pakistan & 120 & 0.8 \\
\hline Srinivas Rao & 2013 & India & 1102 & 1.5 \\
\hline Goel G & 2013 & India & 546 & 2.6 \\
\hline MURMU & 2017 & India & 79 & 2.5 \\
\hline Present study & 2017 & India & 81 & 1.2 \\
\hline
\end{tabular}

Histo-pathological evidence of tuberculous granulomas in tissue samples leads to definitive diagnosis of genital tuberculosis. The technique is easy, quick and cheap and provides characteristic features of MTB. The reported incidence from various studies ranges from $0 \%$ to $4.92 \%$. The low prevalence of $\mathrm{M}$. tuberculosis in endometrial biopsy may be due to various reasons. Due to secondary nature of the genital tuberculosis, the infecting organisms are sparse in number, the sampled site may not represent the infected area or infection may be limited to the fallopian tube. Moreover, due to the cyclical shedding of the endometrium, granulomas do not have enough time forms; so, the endometrium may not show evidence of tuberculosis in all the cycles. The incidence may also be 
lower because of improved health care facilities over the years.

\section{CONCLUSION}

Tuberculous endometritis as a cause of infertility is still a major problem in the developing countries; any woman having infertility and in which the cause cannot be ruled out, should be investigated for tuberculosis. Therefore, in countries where TB is endemic, early and aggressive strategies should be pursued to diagnose and treat TB. A multi-pronged approach to diagnosis increases the chances of successfully diagnosing this destructive disease.

Funding: No funding sources Conflict of interest: None declared

Ethical approval: The study was approved by the Institutional Ethics Committee

\section{REFERENCES}

1. Devasia RA, Blackman A, Gebretsadik T, Griffin M, Shintani A, May C. et al. Fluoroquinolone resistance in Mycobacterium tuberculosis: the effect of duration and timing of fluoroquinolone exposure. Am J Respir Crit Care Med. 2009;180(4):365-70.

2. World Health Organisation (WHO). Global TB Report 2016. Geneva: World Health Organisation (WHO); 2016 WHO/HTM/TB 2016.

3. Thangappah RB, Paramasivan CN, Narayan S:Evaluationg PCR, culture and HPE for diagnosis of female genital tuberculosis; Indian J Med Res. 2011 $\mathrm{Jul} ; 134(1): 40$.
4. World health organisation; practical considerationsXpert MTB $\backslash$ RIF implementation manual, technical and operational 'How-to'; Geneva Switzerland, WHO.2014;8-9.

5. Saxena R, Shrinet K, Jain M. Comparative study of genital tuberculosis diagnosis in women with infertility. Int J Sci Res. 2017;6(7):817-9.

6. Sharma JB, Kriplani A, Dharmendra S, Chaubey J, Kumar S, SharmaSK. Role of Gene Xpert in diagnosis of female genital tuberculosis: a preliminary report. Eur J Obstet Gynecol Reprod Biol. 2016;207:237-8.

7. Kafeel S, Mushtaq H, Alam S. Endometrial histological findings in infertile women. J Islamabad Med \& Dental Coll. 2012;2102(2):61-4.

8. Goel G, Khatuja R, Radhakrishnan G, Agarwal R, Agarwal S, Kaur I. Role of newer methods of diagnosing GTB in infertile women. Indian J Pathol Microbiol 2013;56(2):155-7.

9. Kohli MD, Nambam B, Trivedi SS, et al. PCR based evaluation of tubercular endometritis in infertile women of North India. J Reprod Infertil. 2011;12(1):9-14.

10. Prasad S, Singhal M, Negi SS, Gupta S, Singh S, Rawat DS et al. Targeted detection of $65 \mathrm{kDa}$ heat shock protein gene in endometrial biopsies for reliable diagnosis of genital tuberculosis. Eur $\mathbf{J}$ Obstet Gynecol Reprod Biol. 2012;160(2):215-8.

Cite this article as: Garg R, Agarwal N, Gupta M. Genexpert test and endometrial histological findings in infertile women. Int J Reprod Contracept Obstet Gynecol 2018;7:1480-3. 